\title{
The Impact of Social Capital on Satisfaction with National Policy
}

\author{
Soonae Park* and Dukyun Hwang**
}

\begin{abstract}
This study analyzes the impact of social capital on national policy satisfaction in Korea. Although social capital has been investigated in previous studies, most of them have been limited to the local government level. This study concerns national policies and uses data from the 2007 Survey of Citizen Perceptions of the Public Sector. In total 1,200 people responded from across the country. Using factor analysis, social capital factors were extracted: participation in political networks, participation in nonpolitical networks, trust in others, and altruism. Trust in others was statistically significant to all levels of policy satisfaction; however, other variables were significant only to certain policies. Unexpectedly, participation in political networks, by means of political demonstrations and online debate, was not significant with regard to satisfaction with any policy.
\end{abstract}

Keywords: Social Capital, Policy Satisfaction, Citizen Participation

\section{INTRODUCTION}

This study explored the impact of social capital on national policy satisfaction. Although social capital is not a strong predictor in all cases, it is certainly a powerful enough predictor of several things such to be well worth research attention (Putnam 2000). In fact, there has been considerable research on social capital, covering topics from definition building to analysis of impact on economic development. However, most research has focused on the local or state level using aggregated data. If, as is the case in the United States, local governments are well organized, decentralized, and autonomous, then it is appropriate to use cross-sectional analysis to illustrate differ-

\footnotetext{
* Soonae Park is an associate professor at the Graduate School of Public Administration, Seoul National University. She received her doctoral degree at University of Michigan and research interests include organizational behavior, government performance and environmental policy.

** Dukyun Hwang is a doctoral student at Cleveland State University.
}

Manuscript received January 2009; out for review January 2009; review completed February 2009; accepted February 2009.

The Korean Journal of Policy Studies, Vol. 23, No. 2, 201-223 (2009)

(C) 2009 by the GSPA, Seoul National University 
ences among them with respect to regional social capital and government performance. However, if in the absence of matured decentralization or in cases in which local governments have inadequate resources to function autonomously, it is difficult to apply comparisons as prior studies have. This study measured differential satisfaction with various national policies whose impacts are not limited to certain regions, rather than with local performances.

For this study, the first step was to define social capital and policy satisfaction. Michael Woolcock (2001) summarized the diverse concepts of social capital and suggested that there has been a convergence toward networks and the associated norms of reciprocity. Concerning Woolcock's argument, people's participation in local community activities is measured to represent networks. Public satisfaction with government services is an important goal of national policies, albeit a subjective one. The existing literature adopted economic growth as an objective indicator and explained it based on social capital. Such variables are usually related to public performances. However, people have diverse levels of satisfaction with government. For example, if there is a minimal decrease in the crime rate, some people deem it to be a great achievement, while others consider it to be unexceptional or even disappointing. The improvement of environmental conditions by public services and the improvement of public performance can induce an increase in the people's satisfaction. Such improvement in performance constitutes a sufficient condition for satisfaction with public services. However, it is impossible to say that an improvement in performance is a necessary condition for satisfaction. According to the expectation disconfirmation theory, satisfaction can be increased when performance is consistent but the level of expectation decreases. The present study utilized data from a national survey in Korea that asked about satisfaction with several national policies.

This study investigated the relationship between social capital and national policy satisfaction on the assumption that performance variations among local governments were not significant. It is hoped that the results will improve understanding of individuals' diverse evaluations of the same policy and thus contribute to policy satisfaction.

\section{CONCEPTS AND LITERATURE REVIEW}

\section{Social Capital}

Since Lyda Judson Hanifan referred to social capital as "tangible assets that count for most in people's daily lives" (Hanifan 1920, 78), many researchers, like Douglas 
North and Mancur Olson, have treated the concept of social capital as encompassing institutional relationships and government structures. Pierre Bourdieu focused on the benefits accruing to individuals by virtue of participation in organizations: "Social capital is the aggregate of the actual or potential resources which are linked to possession of a durable network of more or less institutionalized relationship of mutual recognition" (Bourdieu 2001, 248-249). Related to the aspect of networks and reciprocity among people, many studies have tried to understand the impact of social capital on society. Coleman focused on the function of social capital and its mechanisms. He distinguished social capital from the ability to obtain social capital by membership in different social structures (Portes 1998, 6). Traditional studies in social capital aim to establish more clear concepts, distinguishing the possessors of social capital, the source of social capital, and the resources themselves (Portes 1998, 2).

Although more diverse definitions emerged with a number of theoretical analyses, and empirical studies sought to understand the impact of the resources, the meaning of social capital remains focused on "the ability of actors to secure benefits by virtue of membership in social networks or other social structures" (Portes 1998). On the other hand, several studies approached social capital with a focus on cooperation and trust. Fukuyama emphasized the necessity of trust, which is embedded in cultural factors to achieve economic success (Fukuyama 2000). Although Putnam (2000) suggested a relatively clear concept of social capital as connection with social networks and the norms of reciprocity and trustworthiness, still social capital is a mixture of disparate ideas like trust, networks, cooperation, participation, reciprocity, norms of social organization, and information sharing. Recent studies use diverse combinations of such ideas, and they apply social capital to explain diverse social phenomena as well as economic growth (Durlauf 2002). Regarding this trend, Portes (1998) warned against over-versatility, saying that "social capital comes to be applied to so many events and in so many different contexts as to lose any distinct meaning" (Portes 1998). This study measured social capital based on several variables such as participation, altruism, and trust, and basically focused on individual social capital. Although social capital is related to social organization and relationships with others, the purpose of this study is not to identify social capital, but to understand the influence of social capital on individuals' policy satisfaction-a subjective perception of the overall services provided under the name of policy. Therefore, the unit of this study is the individual, based on randomized national data.

Even though there is growing evidence that social capital contributes significantly to sustainable development (Feldman et al. 1999), some aspects of social capital are controversial, such as measurement issues, impacts, and explanatory power. Using multipurpose survey data from the Italian National Institute of Statistics from a sample 
of 24,000 households, Sabatini (2008) studied relationships between three types of social capital and the quality of economic development in Italy-measured based on human development, the state of urban ecosystems, and an index of social well-being. The three forms of social capital were 'strong family ties' (bonding), 'weak informal ties' (bridging), and 'voluntary organization' (linking). Empirical analysis found linking social capital to have significantly positive effects on human development, while bridging social capital showed a negative relationship (Sabatini 2008). On the other hand, bonding social capital had a negative relationship to human development, but it improved social quality by mitigating labor insecurity (Sabatini 2008). Yip et al. (2007) divided social capital into structural and cognitive aspects; structural social capital was measured by organizational membership while cognitive social capital was measured by trust, reciprocity, and mutual help. Their study sought to estimate the relationship between the state of health and social capital in rural China. Although cognitive social capital had positive relationships with various health outcomes, structural social capital had no statistically significant relationship (Yip et al. 2007). Lindstrom and Axen (2004) assessed the impact of social capital on patient dissatisfaction with health care services. They defined social capital as the combination of social participation, trust, and the miniaturization of community. With survey data from a sample of 3,456 persons over 18 years old who had a regular doctor in Scandinavia, they found that low social capital and the miniaturization of community may induce nonspecific patient dissatisfaction (Lindstrom \& Axen 2004).

Requena (2003) suggested that social capital may be a significant predictor of job satisfaction. He measured social capital based on five factors: trust, social relations, commitment, communication, and influence. He claimed that these are better predictors of job satisfaction than worker and company characteristics or work environment (Requena 2003). Another interesting study focused on diverse happiness levels in 32 nations (Bjornskov 2003). Using World Values Survey data, this study found that Switzerland and Scandinavian countries that show strong social capital seem to have higher levels of happiness and life satisfaction. Bjornskov (2003) performed factor analysis and confirmed that a social capital factor is comprised of trust, perceived corruption, and civic participation. From a similar perspective, Vemuri and Costanza (2006) explored key factors that contribute to life satisfaction in 171 countrieshuman, social, built, and natural capitals. Although they utilized various data sources from the World Values Survey to Freedom House's press freedom rating in order to find the best proxy variables for each, they failed to find a significant proxy for social capital. Instead, they found that the United Nations Human Development Index (HDI) and the value of ecosystem services per $\mathrm{km}^{2}$ explain 72 percent of the variations in life satisfaction at the country level (Vemuri \& Costanza 2006). 
With data from the World Values Survey, the U.S. Benchmark Survey, and a comparable Canadian survey, Helliwell and Putnam (2004) designed equations to explore the subjective evaluations of well-being and life satisfaction. The impact of social capital measured by strength of family, neighborhood, religious, and community ties were taken into consideration. Such social capital is strongly linked to life satisfaction (Helliwell \& Putnam 2004). Related to public performance, Coffe and Geys (2005) measured social capital with the number of organizations per capita in each municipality, electoral turnout, and the crime rate per capita. They found that social capital leads to better quality in the government's financial management (Coffe \& Geys 2005). Adopting objective macro-level indicators of institutional performance and local level data, their research contributes to an expanding research agenda.

With survey data on 114 Iowa communities, Rice (2001) measured social capital as interpersonal trust, civic engagements, and social networks. This analysis found that social capital is very strongly and positively related to government responsiveness and quality of service (Rice 2001). In Knack's (2002) study, an estimate of social capital, as measured by an index of trust, volunteering, and census response, is strongly linked to governmental performance. The 35 criteria adopted in a survey questionnaire were to assess diverse aspects of government performance - for instance, accuracy of revenue and expenditure forecasts, structural balance between revenues and expenditures, the effective use of performance data for policy-making, and the involvement of stakeholders in the development of strategic plans (Knack 2002).

There is a growing consensus that social capital constitutes the ability of actors to secure benefits by virtue of membership in social networks or other social structures. However, this is a potential definition, and there are other discussions related to social capital. Coleman (1998) suggested that social capital is defined by its function, which is not a single entity but a variety of different entities possessing common characteristics. Hence, social capital reflects a social structure and facilitates certain actions of individuals within the structure, adopting three forms: obligations and expectations that depend on the trustworthiness of the social environment; the capacity for information to flow through the social structure in order to provide a basis for action; and the presence of norms accompanied by effective sanctions (Coleman 1988). Through scholarly efforts to define social capital and measure its impact, the concept has evolved.

As a representative study of social capital, Putnam's research in Italy has drawn economists' attention. In his research, social capital is positively and significantly related to the institutional and economic performances of the Italian regions. His study focused on features of social life including networks, norms, and trust that enable participants to act cumulatively more effectively and to pursue shared objectives (Putnam 1993). Put- 
Table 1. Summary of Literature Review

\begin{tabular}{|c|c|c|c|c|}
\hline Author (year) & Social capital variable & Dependent variable & Results & Scope of study \\
\hline $\begin{array}{l}\text { Sabatini } \\
(2008)\end{array}$ & $\begin{array}{l}\text { Bonding social capital: } \\
\text { strong family ties } \\
\text { Bridging social capital: } \\
\text { weak informal ties } \\
\text { Linking social capital: } \\
\text { voluntary organization }\end{array}$ & $\begin{array}{l}\text { Quality of development: } \\
\text { human development, state } \\
\text { of urban ecosystems, and } \\
\text { an index of social } \\
\text { well-being }\end{array}$ & \begin{tabular}{|l|} 
Bonding social \\
capital (-) to \\
human development \\
Linking social \\
capital (+) to quality \\
of urban ecosystems \\
Bridging and linking \\
social capital (+) to \\
human development \\
Bonding social capital \\
$(-)$ to labor insecurity \\
\end{tabular} & $\begin{array}{l}\text { National survey } \\
\text { in Italy }\end{array}$ \\
\hline $\begin{array}{l}\text { Yip et al. } \\
(2007)\end{array}$ & $\begin{array}{l}\text { Structural social capital: } \\
\text { organizational membership } \\
\text { Cognitive social capital: } \\
\text { trust, reciprocity, and } \\
\text { mutual help }\end{array}$ & $\begin{array}{l}\text { Self-reported general } \\
\text { health } \\
\text { Psychological health } \\
\text { Subjective well-being }\end{array}$ & $\begin{array}{l}\text { Cognitive social capital } \\
(+)\end{array}$ & $\begin{array}{l}\text { National survey } \\
\text { in China }\end{array}$ \\
\hline $\begin{array}{l}\text { Lindstrom and } \\
\text { Axen (2004) }\end{array}$ & $\begin{array}{l}\text { Combination of social } \\
\text { participation and } \\
\text { generalized trust }\end{array}$ & $\begin{array}{l}\text { Patient dissatisfaction with } \\
\text { health care service }\end{array}$ & Low social capital (-) & $\begin{array}{l}\text { National survey } \\
\text { in Scandinavia }\end{array}$ \\
\hline $\begin{array}{l}\text { Requena } \\
\text { (2003) }\end{array}$ & $\begin{array}{l}\text { Trust, social relations, } \\
\text { commitment, communication }\end{array}$ & $\begin{array}{l}\text { Quality of life at work } \\
\text { Job satisfaction }\end{array}$ & $\begin{array}{l}\text { (+) except } \\
\text { communication }\end{array}$ & $\begin{array}{l}\text { National survey } \\
\text { in Spain }\end{array}$ \\
\hline $\begin{array}{l}\text { Vemuri and } \\
\text { Contanza } \\
\text { (2006) }\end{array}$ & $\begin{array}{l}\text { Freedom House's press } \\
\text { freedom rating }\end{array}$ & Life satisfaction & Not significant & 171 countries \\
\hline $\begin{array}{l}\text { Coffe and } \\
\text { Geys (2005) }\end{array}$ & $\begin{array}{l}\text { The number of a wide } \\
\text { variety of organizations per } \\
\text { capita in each municipality } \\
\text { Electoral turnout } \\
\text { Crime rate per capita }\end{array}$ & $\begin{array}{l}\text { Total government revenues } \\
\text { and total expenditures } \\
\text { during fiscal year } 2000\end{array}$ & $(+)$ & $\begin{array}{l}305 \text { Flemish } \\
\text { municipal } \\
\text { governments }\end{array}$ \\
\hline $\begin{array}{l}\text { Helliwell and } \\
\text { Putnam (2004) }\end{array}$ & $\begin{array}{l}\text { The strength of family, } \\
\text { neighborhood, religious, } \\
\text { and community ties }\end{array}$ & $\begin{array}{l}\text { Subjective evaluations of } \\
\text { well-being, happiness, } \\
\text { and life satisfaction }\end{array}$ & $(+)$ & $\begin{array}{l}\text { World Values } \\
\text { Survey, U.S. } \\
\text { Benchmark } \\
\text { Survey, and } \\
\text { Canadian survey }\end{array}$ \\
\hline $\begin{array}{l}\text { Bjornskov } \\
\text { (2003) }\end{array}$ & $\begin{array}{l}\text { Social capital factors: } \\
\text { trust, civic participation, } \\
\text { and perceived corruption }\end{array}$ & Life satisfaction & $(+)$ & $\begin{array}{l}\text { World Values } \\
\text { Survey } \\
32 \text { countries }\end{array}$ \\
\hline$\overline{\text { Knack (2003) }}$ & $\begin{array}{l}\text { Trust, volunteering, } \\
\text { and census response }\end{array}$ & $\begin{array}{l}\text { Overall government } \\
\text { performance as well as } \\
\text { five specific types of } \\
\text { performance }\end{array}$ & $(+)$ & $\begin{array}{l}\text { Survey of } 49 \text { state } \\
\text { governments by } \\
\text { the Government } \\
\text { Performance } \\
\text { Project }\end{array}$ \\
\hline Rice (2001) & $\begin{array}{l}\text { Interpersonal trust, } \\
\text { civic engagements, } \\
\text { and social networks }\end{array}$ & $\begin{array}{l}\text { Subjective judgments } \\
\text { concerning responsiveness } \\
\text { to complaints and quality of } \\
\text { the services }\end{array}$ & $(+)$ & $\begin{array}{l}113 \text { lowa } \\
\text { communities }\end{array}$ \\
\hline
\end{tabular}


nam also warned in his book Bowling Alone (2000) that there would be a decline in the participation of Americans in politics, civic groups, religious organizations, trade unions, and professional organizations, as well as in informal socializing. Moreover, he argued that active membership in community groups is decreasing and that this is negatively influencing social outcomes. He posited that television has been the main culprit in the decline of social capital; people are so busy watching that they are left with less time to socialize. Reconsidering Putnam's (1993) study, he studied twenty local governments possessing an identical form but dramatically different environmental settings. Certain governments proved to be inefficient, lethargic, and corrupt, while others were successful, promoting investment and economic development. To account for such differences in government performances, strong traditions of civic engagement constitute the most effective predictor: voter turnout, newspaper readership, membership in choral societies and literary circles, and so on. He found that some civic regions have more mature workings of democracy and successful local government, although each government has a similar form.

In comparison with Italian regions, Korea's local governments have a short history. In Italy, powerful regional governments started in 1970, while the direct election of local heads of government in Korea began in 1995. Moreover, the autonomy of local governments is not strong enough to provide differential public services to their residents because of inadequate financial capacity and stringent regulations imposed by the central government. Most local governments are dependent on financial support from the central government; therefore, the central government intervenes in many local government projects. Although a decentralized government system has been operating for more than 10 years, it does not provide appropriate conditions to compare performance among local governments. Considering local characteristics in Korea, this study analyzed individual satisfaction with national policies. Social capital is constituted by the web of cooperative relationships among citizens that facilitates collective action to solve problems (Brehm \& Rahn 1997). Thus, variations in social capital can be explained by the psychological involvement of citizens with their communities, and such variation affects the confidence of citizens in national institutions beyond their evaluations of actual performance (Brehm \& Rahn 1997).

On the other hand, citizens' participation to express their demands regarding service delivery or decision-making exerted a positive impact on the external or system responsiveness dimension of efficacy (Finkel 1985). Defining political efficacy as the belief that one has the skills to influence the political system, Zimmerman (1989) found that political efficacy was greater for members of voluntary political organizations than for nonmembers (Zimmerman 1989). Although political participation in previous studies is related to participation in political campaigns and voting, willing- 
ness to participate in collective actions to solve common problems in a community is also based on reciprocity and trust among members.

\section{Policy Satisfaction}

Policy satisfaction, as a dependent variable of this study, enfolds two characteristics: evaluation of government activities and citizen satisfaction with the quality of public service. However, there is a lack of consensus among scholars about the relationship between government performance and citizen satisfaction. Kelly (2003) suggested that a positive relationship may exist but that the success of service performance improvement should be tested by customer satisfaction. Performance, as outputs of government activities, can be easily changed to available objective data, through internal measures of quantitative aspects of services, but different perceptions of citizens based on receiving unequal services cannot be measured by performance data. The marketing studies, in addition, suggest that subjective satisfaction is based on the relationship between service expectation and service experience (Kelly 2003). Even when the government provides equal quality services to the public, each person with his or her diverse expectations and experiences can have different perceptions about those services. People who have served in the military could have different levels of satisfaction with veterans' pensions, for example. Moreover, when a policy has several sub-services, it is not easy to identify its outputs, and thus people's perceptions of a policy can not be determined by a single output. Instead, policy satisfaction is the overall evaluation of a government policy. The policies discussed in this study include diplomacy and defense, education, environment, labor, welfare, arts and culture, and health and medical services.

DeHoog et al. (1990) also studied the relationship between social capital and policy satisfaction. They suggested that for citizen satisfaction with urban services, community attachment is a significant factor. They combined five items in their concept of community attachment: degree of attachment to the community, how sorry the respondent would be to leave the city, the number of friends who live in the city, the number of relatives who live in the city, and length of residence (DeHoog et al. 1990). Such items are related to social capital, which involves relationships with neighbors, regional community, and personal networks. In addition, social capital focuses on citizens' participation in both formal and informal organizations. Boix and Posner (1998) discussed the relationship between cooperative capacity and the performance of political institutions based on five models: rational voters and competitive elites, rule compliance, civic virtue, bureaucratic efficiency, and elite accommodation. While these five models concern a perfectly competitive democracy, the reduced transaction costs, 
cooperation with bureaucratic elites, promoted cooperation across network boundaries, and consideration of everyone's benefits rather than certain members, social capital increases the performance of government. Although it is hard to verify that improvement of government performance guarantees an increased satisfaction level, it is worth studying the relation between social capital and policy satisfaction.

Coleman (1988) also studied the relation between social capital and policy satisfaction. He suggested that people with similar interests can share information with relative efficiency, because information sharing is a kind of byproduct of their relationships (Coleman 1988). For instance, the purpose of a meeting of alumni is to maintain friendships, but information about diverse social issues is also shared through conversations among members. However, information shared in their relations may be not only about the output of government activities but also about outcomes, irrespective of the credibility of such information. In most cases, outcome information that is shared in social relations is subjective. If the perceptual information gap between output information from government and subjective outcome information from the public appears to be great, public trust in government will decline (Welch et al. 2005).

Lastly, citizen satisfaction is determined by experience with services from government and expectations which each person previously has before receiving the services. Hence, it is important to note the impact of social capital on expectations. However, studies related to expectations about public services are rare, and its impact is not clear. Although social capital is considered to influence expectations, it is questionable whether it is possible to adopt the expectations that are formed among individual relationships to policy satisfaction.

\section{CONCEPTUAL FRAMEWORK}

Although there are common factors and similar tendencies in regard to the selection of research methods, it is possible to find academically determined concepts and measurement methods with regard to social capital.

Grootaert and World (1998) expressed the functions of social capital as the following: information sharing, coordination of activities, and collective decision-making. First, information problems refer to problems derived from inadequate or inaccurate information. However, social capital facilitates communication and amplifies information regarding the trustworthiness of others; networks of formal and informal contacts are made to decrease the dangers of inadequate or inaccurate information. Second, the coordination of activities is important to the successful implementation of collective decisions or public policy—and uncoordinated or opportunistic behavior can lead to 
market and governmental failure. A purpose of coordination is the accomplishment of the common goal of the organization, and social capital embodies past success at collaboration, which can serve as a resource for future collaboration and coordination (Putnam 2001). Third, collective decision-making leads to efficient reciprocity and social capital fosters sturdy norms of generalized reciprocity through stable expectations (Putnam 2001).

In order to measure the intimacy of a civic engagement network, the participation level in community activities can be utilized. Schuller (2000) measured participation as membership in voluntary organizations, churches, and political parties. In a similar context, Putnam argued that active membership in community groups is positive for the creation and maintenance of social capital (Putnam 2000). There are diverse communities that people can participate in, including formal and informal organizations. In this study, regional communities, political demonstrations, parent associations, alumni associations, voluntary activities, and political debates via the Internet are treated as networks.

The other variable is trust in others. Woolcock (2001) thought that trust is not a part of the definition or sources of social capital but its consequence. Trust is a vitally important entity in its own right, but can be regarded as an outcome of repeated interactions. Therefore, trust is appropriate to use as a proxy (Putnam 2001). In this study, questions regarding levels of trust in others have been asked. Previous studies on policy satisfaction have used trust in government (Van De Walle \& Bouckaert 2003; Christensen \& Laegreid 2005; Welch et al. 2005). On the other hand, trust in others has been used in studies on social capital or governance (Sullivan \& Transue 1999; Schuller et al. 2000). Sullivan and Transue (1999) stated that generalized interpersonal trust as a form of social capital supports democratic governance. This study assumed that the outcome of democratic governance is national policies and used trust in others as an independent variable with regard to policy satisfaction.

The last independent variable to constitute social capital is altruism, the selfness concern for others' welfare. There are various activities based on altruism, from blood donations to financial donations. According to Putnam (2001), altruism is not a part of the definition of social capital; however, empirically, it turns out that altruism is related to social connectedness: Those who have strong altruism tend to be more connected. That is to say, philanthropists frequently go to many clubs and to church; the point is not how much money they have. To measure altruism, the willingness to donate money to charitable organizations is estimated.

The satisfaction levels with national policies constitute the dependent variables. Generally, GDP per capita has been used as a dependent variable to estimate the relationships between social capital and economic growth. In this study, national policy 
satisfaction was adopted to measure the individual political efficacy representing a form of political orientation. What distinguishes the current study from other social capital studies is a dependent variable. Economic growth is not the only final outcome of public policies or services but one of many. On the other hand, policy satisfaction is related to the final evaluation of a policy process, although it is difficult to objectively measure it. Therefore, policy satisfaction is a useful indicator of the final impact of public policies. This study was based on national policies; their impacts are not limited to certain regions. For example, although real estate policies have been an important issue in Korea, they are not addressed in this study as they focus on certain regions exclusively, in order to control the sharp increase in land prices in 2006. Instead, this study focuses on policies related to diplomacy and defense, education, the environment, labor, welfare, art and culture, and health and medical services.

The following control variables are included: region, sex, age, political attitude, education level, monthly income, daily life satisfaction, and policy understanding. To control the impact of regional characteristics, respondents' regions and their sizes were considered. Sex and age are used to control the impact of different policy concerns related to gender and generation. In Korea, the compulsory military service is limited to young males; consequently, there may be different interest levels between males and females in regard to the defense policy. Because policies are the results of political decisions, respondents may have different satisfaction levels depending on their political orientation. To consider the respondents' intellectual levels and economic conditions, their academic backgrounds and monthly incomes were included. As one of the control variables, the policy understanding level was used to control the impact of respondents' knowledge levels. Policy understanding implied policy literacy, which involves the ability to recognize and analyze information about the policy, and finally affects policy satisfaction.

\section{METHOD AND DATA}

Considerable research about social capital has employed either country-level data or aggregated data from individuals. Portes and Landolt (1996) argued that collective social capital cannot simply be the sum of individual social capital. However, researchers using aggregated data at the country level can avoid such problems. Schullar et al. (2000) suggested that social capital has been aggregated across different levels and that the validity of social capital depends on its contextualization. The aggregated data from individuals is not an exception. They also suggest that the total number of people who belong to organizations indicates little about the strength of social capital if it is not 
accompanied by information about what people do as members. Therefore, it is important to consider the environmental information of respondents.

A national survey was carried from December 2006 to January 2007 under the name of 'Citizen Perception Survey' of the Knowledge Center for Public Administration and Policy in Seoul National University. The questionnaire covered various topics including people's perception of public policies, administrative processes, public issues, civil organizations' activities, participation in social meetings, trust, and respondents' personal information. In total 1,200 peoples were surveyed from across the country. Survey respondents were selected proportionally by population distributions from each region. Of the respondents, 50.7 percent were male and 49.3 percent female. The age distribution of respondents was as follows: under thirty, 20.9 percent; thirties, 24 percent; forties, 22.8 percent; and fifties and over, 32.3 percent. The questionnaire consisted of a seven point scale with 135 questions.

In order to identify participation variables, an exploratory principal factor analysis with varimax rotation was conducted using an eigenvalue of 1.0 or greater. Respondents were asked to indicate the frequency of participation in diverse networks. Two factors were extracted among six activities. As shown in table 2, the first group included regional communities, parent associations, voluntary activities, and alumni associations, and the second group included political debates through the Internet and political demonstrations.

Including the two factors, thirteen variables were used in this study (see table 3). Regarding the political aspects of each category, the two factors are nonpolitical par-

Table 2. Results of Factor Analysis: Participation Variables

\begin{tabular}{l|c|c|c|c}
\hline \multirow{2}{*}{ Participation variables } & \multicolumn{2}{|c|}{$\begin{array}{c}\text { Level of participation in } \\
\text { nonpolitical networks (Factor 1) }\end{array}$} & $\begin{array}{c}\text { Level of participation in } \\
\text { political networks (Factor 2) }\end{array}$ \\
\cline { 2 - 5 } & Factor loading & Factor score & Factor loading & Factor score \\
\hline Regional communities & 0.831 & 0.504 & -0.037 & -0.239 \\
\hline Parent associations & 0.747 & 0.411 & 0.132 & -0.085 \\
\hline Voluntary activities & 0.665 & 0.305 & 0.359 & 0.113 \\
\hline Alumni associations & 0.446 & 0.211 & 0.214 & 0.055 \\
\hline $\begin{array}{l}\text { Political debates through } \\
\text { the Internet }\end{array}$ & 0.065 & -0.179 & 0.862 & 0.659 \\
\hline Political demonstrations & 0.230 & -0.049 & 0.736 & 0.519 \\
\hline Eigenvalue & \multicolumn{2}{|c|}{2.382} & \multicolumn{2}{c}{1.043} \\
\hline Percentage of variance & \multicolumn{2}{|c|}{39.702} & \multicolumn{2}{c}{57.078} \\
\hline Cumulative variance & \multicolumn{2}{|c|}{39.702} \\
\hline
\end{tabular}


Table 3. Descriptive Statistics of Variables

\begin{tabular}{|c|c|c|c|c|c|c|c|}
\hline Category & Variable & Definition & Scale & Min & Max & Mean & SD \\
\hline \multirow{4}{*}{$\begin{array}{l}\text { Independent } \\
\text { variable }\end{array}$} & Par1(a) & $\begin{array}{l}\text { Level of participation in nonpolitical } \\
\text { networks }\end{array}$ & & 1.43 & 7.15 & 3.045 & 1.211 \\
\hline & Par2(b) & Level of participation in political networks & & 1.18 & 5.37 & 1.610 & 0.754 \\
\hline & Tru & Trust in others & 7-point & 1 & 7 & 4.502 & 1.311 \\
\hline & Alt & Willingness to donate & 7-point & 1 & 7 & 4.044 & 1.705 \\
\hline \multirow{7}{*}{$\begin{array}{l}\text { Dependent } \\
\text { variable }\end{array}$} & \multirow{7}{*}{ Sat } & $\begin{array}{l}\text { Satisfaction with diplomacy and } \\
\text { defense policy }\end{array}$ & \multirow{7}{*}{ 7-point } & 1 & 7 & 2.975 & 1.261 \\
\hline & & Satisfaction with education policy & & 1 & 7 & 2.720 & 1.261 \\
\hline & & $\begin{array}{l}\text { Satisfaction with health and medical } \\
\text { services policy }\end{array}$ & & 1 & 7 & 3.320 & 1.302 \\
\hline & & Satisfaction with welfare policy & & 1 & 7 & 3.308 & 1.366 \\
\hline & & Satisfaction with environmental policy & & 1 & 7 & 3.266 & 1.274 \\
\hline & & Satisfaction with art and culture policy & & 1 & 7 & 3.408 & 1.225 \\
\hline & & Satisfaction with labor policy & & 1 & 7 & 2.956 & 1.239 \\
\hline \multirow{14}{*}{$\begin{array}{l}\text { Control } \\
\text { variable }\end{array}$} & \multirow{7}{*}{ Und } & $\begin{array}{l}\text { Understanding of diplomacy and } \\
\text { defense policy }\end{array}$ & \multirow{7}{*}{ 5-point } & 1 & 5 & 1.798 & 1.116 \\
\hline & & Understanding of education policy & & 1 & 5 & 1.293 & 0.683 \\
\hline & & $\begin{array}{l}\text { Understanding of health and medical } \\
\text { service policy }\end{array}$ & & 1 & 5 & 3.194 & 1.204 \\
\hline & & Understanding of welfare policy & & 1 & 5 & 1.435 & .827 \\
\hline & & Understanding of environment policy & & 1 & 5 & 2.021 & 1.160 \\
\hline & & Understanding of art and culture policy & & 1 & 5 & 1.915 & 0.876 \\
\hline & & Understanding of labor policy & & 1 & 5 & 6.466 & 1.141 \\
\hline & $\operatorname{lnc}$ & Monthly income(c) & 10-point & 1 & 10 & 4.418 & 2.374 \\
\hline & Rei & Region of residence(d) & dummy & & & & \\
\hline & Sex & Male or female & dummy & & & & \\
\hline & Age & Age & & 19 & 81 & 43.01 & 14.58 \\
\hline & Edu & Education level(e) & 4-point & 1 & 4 & 3.055 & 0.966 \\
\hline & Poa & Political orientation(f) & 5-point & 1 & 5 & 3.050 & 0.911 \\
\hline & Dal & Satisfaction with daily life & 5-point & 1 & 5 & 2.720 & 0.863 \\
\hline
\end{tabular}

\footnotetext{
(a) From Table 2, Par1 $=(\mathrm{b} 29 \times 0.504)+(\mathrm{b} 30 \times 0.41)+(\mathrm{b} 32 \times 0.211)+(\mathrm{b} 34 \times 0.305)$.

b29: participation in regional communities; factor score coefficient $=0.504$

b30: parent associations; factor score coefficient $=0.411$

b32: alumni associations; factor score coefficient $=0.211$

b34: voluntary activities; factor score coefficient $=0.305$

(b) From Table 2, Par2 $=($ b31 0.519$)+($ b33 $\times 0.659)$

b31: participation in political demonstrations; factor score coefficient $=0.519$

b33: political debates through the Internet; factor score coefficient $=0.659$

(c) From under 990,000 won to over 50,000,000 won (the exchange rate in December 2006 was 929.60 won to US $\$ 1$ )

(d) Seoul, Inchon, Kyonggi, Kangwon, Daejeon, Chungnam, Chungbuk, Gwangju, Jeonnam, Jeonbuk, Daegu, Kyongbuk, Kyungnam, Pusan, and Ulsan

(e) From less than elementary school completion to more than the first university degree

(f) From conservative to progressive
} 
ticipation and political participation; political demonstrations and political debates through the Internet are clearly political activities; however, the others are difficult to see as political activities. An interesting point is that the mean value of the level of participation in political networks was 1.61 , which is very low considering its minimum value of 1.18 and maximum value of 5.37. The mean for the political demonstrations variable was 1.293 and the mean for political debates through the Internet was 1.425 .

Since the traffic accident involving a U.S. military vehicle that left two middle school students dead in Korea in 2002, the candlelight rally has become a form of national demonstration. In 2004 and 2008, there were national demonstrations in the form of candlelight rallies. However, although many people participated in these rallies, they were recognized as cultural festivals. Moreover, the government prohibits any outdoor political demonstration that there is no preliminary report. Online political debates are possible on various Internet portals and on government websites, but such debates require Internet access. Internet literacy is high among young people, but the mean value for political debates through the Internet for those over fifty was 1.197, which is close to no participation. The mean value for trust in others is close to 4.502, and the standard deviation is 1.311; thus, the trust level is almost normal. An altruism variable shows similar results; the mean value for willingness to donate is 4.043 , and the standard deviation is 1.705 .

Figure 1 shows the research framework with the variables introduced above. A linear regression was performed to estimate the direction and intensity of relationships among the variables.

Figure 1. Research Framework

\begin{tabular}{|ll}
\hline Individual social capital & Satisfaction with national policies \\
- Trust & - Diplomacy and defense \\
- Trust in others & - Education \\
- Participation & - Environment \\
- Participation in political networks & - Labor \\
- Participation in nonpolitical networks & - Welfare \\
- Altruism & - Art and culture \\
- Willingness to donate & - Health and medical services \\
Control variables - region, size of region, sex, age, political attitude, education level, \\
monthly income, satisfaction with daily life, and policy understanding
\end{tabular}




\section{RESULTS}

As mentioned above, participation in political and nonpolitical networks is drawn from the results of factor analysis. In addition, linear regression analysis was performed to examine whether social capital is significant with regard to explaining policy satisfaction. Tables 4 and 5 summarize the multiple regression results for each policy. The Durbin-Watson values for the multiple regression results ranged from 1.576 to 1.790; consequently, there were no serious autocorrelation problems. ${ }^{1}$ Variance inflation factor (VIF) values of variables in the model were less than 2.6, and the multicollinearity was also not severe. ${ }^{2}$ However, the explanatory powers of the independent variables were fairly low; R-squared values ranged from 0.094 to 0.155 . These results indicate that the presented models can partially explain the variation in policy satisfaction, and other variables that were not included in the model may explain the remaining variance.

With regard to all regression results in this study, only trust was significantly associated with all levels of policy satisfaction. This means that those with higher trust in others exhibited greater satisfaction with national policies. Trust in others is a representative constituent of social capital; Putnam (2001) and Woolcock (1998) suggested that trust in others is important in explaining the difference in the performance of the local government. However, in regard to citizen satisfaction with local government, trust in government or officials is used as an independent variable. This study connected trust in others to policy satisfaction; the impact of trust in others on policy satisfaction level was positively significant. Based on comparative research across countries, Sullivan and Transue (1999) found that the degree to which people perceive others as threatening is related to robust democracies. A low degree of threat perception indicates strong trust in others, and policy satisfaction is a consequence of the political structure. National policy is formed by means of administrative processes under the political system, and the satisfaction with such policies is a result of policy evaluation. Therefore, trust in others, which is significant with regard to all policies, possessing a positive coefficient in this study, coincides with prior social capital studies.

1. A Durbin-Watson value of less than 2 implies that there is evidence of positive serial correlation; however, this does not indicate a serious concern with regard to autocorrelation in this study.

2. In the case of education policy, the VIF value for the education level variable is 2.599. The square root of 2.6, 1.612, means that the standard error for the coefficient of the education level variable is 1.612 times as large as it would be if the variable was uncorrelated with the other variables. 
Table 4. Multiple Regression Results for Diplomacy and Defense Policy, Education Policy, Health and Medical Services Policy, and Welfare Policy

\begin{tabular}{|c|c|c|c|c|}
\hline Variable & Beta & S.E. & $T$ & Sig. \\
\hline \multicolumn{5}{|l|}{ Diplomacy and defense policy } \\
\hline Participation in political networks & 0.022 & 0.055 & 0.698 & 0.485 \\
\hline Participation in nonpolitical networks & -0.102 & 0.035 & -3.213 & 0.001 \\
\hline Willingness to donate & 0.071 & 0.023 & 2.383 & 0.017 \\
\hline Trust in others & 0.149 & 0.029 & 5.135 & 0.000 \\
\hline \multicolumn{5}{|l|}{ R-squared: 0.110; Durbin-Watson: 1.717} \\
\hline \multicolumn{5}{|l|}{ Education policy } \\
\hline Participation in political networks & 0.040 & 0.053 & 1.272 & 0.204 \\
\hline Participation in nonpolitical networks & -0.083 & 0.034 & -2.565 & 0.010 \\
\hline Willingness to donate & 0.028 & 0.022 & 0.919 & 0.358 \\
\hline Trust in others & 0.143 & 0.028 & 4.891 & 0.000 \\
\hline \multicolumn{5}{|l|}{ R-squared: 0.094; Durbin-Watson: 1.576} \\
\hline \multicolumn{5}{|l|}{ Health and medical services policy } \\
\hline Participation in political networks & 0.059 & 0.053 & 1.914 & 0.056 \\
\hline Participation in nonpolitical networks & -0.066 & 0.034 & -2.104 & 0.036 \\
\hline Willingness to donate & 0.100 & 0.023 & 3.405 & 0.001 \\
\hline Trust in others & 0.136 & 0.028 & 4.740 & 0.000 \\
\hline \multicolumn{5}{|l|}{$R$-squared: 0.130; Durbin-Watson: 1.790} \\
\hline \multicolumn{5}{|l|}{ Welfare policy } \\
\hline Participation in political networks & -0.002 & 0.055 & -0.063 & 0.950 \\
\hline Participation in nonpolitical networks & -0.051 & 0.035 & -1.635 & 0.102 \\
\hline Willingness to donate & 0.092 & 0.023 & 3.151 & 0.002 \\
\hline Trust in others & 0.139 & 0.029 & 4.945 & 0.000 \\
\hline
\end{tabular}

R-squared: 0.155; Durbin-Watson: 1.726

However, participation in political networks is not significant with regard to satisfaction with any policy and did not explain the level of policy satisfaction. The participation in political networks implies representation of inherent political opinions and interests with regard to the policy process. Several past studies suggested that participation in the decision-making process has a positive effect on satisfaction. The distinction in participation level might produce different outcomes from previous studies, which measured participation in the decision-making process, while this study did not guarantee participation in political decision- or policy-making. Although people showed their opinions and interests in certain policies, such participation did not constitute an intervention in the administrative decision-making process.

Political participation is not directly connected to political efficacy, which moti- 
Table 5. Multiple Regression Results for Environmental Policy, Art and Culture Policy, and Labor Policy

\begin{tabular}{l|r|r|r|r}
\hline \multicolumn{1}{c|}{ Variable } & Beta & S.E. & \multicolumn{1}{c}{ T } & Sig. \\
\hline \multicolumn{5}{l|}{ Environmental policy } \\
\hline Participation in political networks & 0.024 & 0.052 & 0.771 & 0.441 \\
Participation in nonpolitical networks & -0.003 & 0.033 & -0.102 & 0.919 \\
Willingness to donate & -0.058 & 0.022 & 1.951 & 0.051 \\
Trust in others & 0.090 & 0.028 & 3.140 & 0.002 \\
\hline$R$-squared: 0.122 ; Durbin-Watson: 1.690
\end{tabular}

R-squared: 0.122; Durbin-Watson: 1.690

\begin{tabular}{|c|c|c|c|c|}
\hline \multicolumn{5}{|l|}{ Art and culture policy } \\
\hline Participation in political networks & 0.030 & 0.049 & 0.997 & 0.319 \\
\hline Participation in nonpolitical networks & -0.012 & 0.031 & -0.391 & 0.696 \\
\hline Willingness to donate & 0.036 & 0.0213 & 1.241 & 0.215 \\
\hline Trust in others & 0.117 & 0.026 & 4.172 & 0.000 \\
\hline \multicolumn{5}{|l|}{ R-squared: 0.156; Durbin-Watson: 1.758} \\
\hline \multicolumn{5}{|l|}{ Labor policy } \\
\hline Participation in political networks & 0.042 & 0.052 & 1.341 & 0.180 \\
\hline Participation in nonpolitical networks & -0.054 & 0.032 & -1.701 & 0.089 \\
\hline Willingness to donate & 0.045 & 0.022 & 1.509 & 0.132 \\
\hline Trust in others & 0.098 & 0.027 & 3.357 & 0.001 \\
\hline
\end{tabular}

R-squared: 0.099; Durbin-Watson: 1.649

vates subjective evaluation of government policy; thus, political efficacy can be considered a necessary condition between political participation and citizen satisfaction. Diverse factors can suppress political efficacy — for example, an unstable political situation in which public demands are barely accepted, the absence of communication channels between policy-makers and the public, and dictatorial characteristics of the administration. Although the impact of political participation is not significant in this study, several studies indicate that political participation creates increased political efficacy, which is correlated to satisfaction levels. The results regarding political participation in the study seem to be a matter of measurement of political participation. Voting and campaign activities that bring about changes to the existing structure may be cognitively different from participation in demonstrations and political debate. According to Finkel's (1987) study of West Germany in mid 1970s, peaceful protest had little effect on political efficacy, while campaign activities had a significant effect (Finkel 1987).

With regard to the participation in nonpolitical networks, there are two interesting aspects. First, it is significant with regard to certain policies: those concerning diplo- 
macy and defense, education, and health and medical services. Such policies do not focus on the interests of specific regions or groups. Nonpolitical networks include regional communities, parent associations, alumni associations, and voluntary activities. Using only these results, it is impossible to say why participation in nonpolitical networks is significant to certain policies and not to others, just that this difference exists. Second, the coefficients are negative. This result is contrary to that of previous studies in social capital. According to previous studies, the participation of community members in health promotion coalitions increases the likelihood of program success (Butterfoss et al. 1996); community participation is an appropriate strategy toward empowerment and capacity building in regard to urban housing, health, and irrigation projects (Paul 1987). Putnam (1993) suggested that the scope of local civic associations laid the foundations for widespread dissemination of information and social trust, creating the conditions underpinning effective governance (Putnam 2000). In previous studies, community participation was found to be connected to community development. However, the results of the current study regarding the relationship between participation in nonpolitical networks and national policy satisfaction levels indicate another form of relationship that is different from the results of previous studies.

Of possible relevance to interpreting these results are information sharing and the existence of an alternative private market for services. Regarding diplomacy and defense policy, performance is decided not only by the government but also by its counterparts in diplomatic negotiations. Sometimes diplomacy and defense policy performance is decided by third countries-for example, unpredictable terror threats and missile experiments by North Korea. In 2006, there were diverse diplomacy issues: diplomatic confrontation over territorial claims to a small island, Dokdo, between South Korea and Japan, the free trade agreement with the United States, and test firing of the multistage Taepodong-2 missile. Such diplomatic incidents induce very sharp conflicts among people. Because most diplomatic problems in 2006 were not solved, and the probability of recurring conflicts continues to exist, information sharing through social relations may cause worse perceptions of government diplomatic performances.

The private market can provide complementary or competitive services to those provided by the government, which may influence people's satisfaction with national policy. In South Korea, education business are highly competitive; there are also many private medical institutions. Generally, the private market provides services that can meet the demands of consumers, and more information about the private market means more diverse services and price structures that consumers can compare with public services. Sometimes, citizens pay for services that they do not consume and there is a single tax price that is not relevant to service quality (Kelly 2003). However, when there are only weak comparable private markets, not only is there little information about pri- 
vate markets, but also it is hard to compare the quality of public and private services.

According to Putnam (2001), altruism is related to social connectedness; thus, altruism is an appropriate proxy of social capital. However, in this study, altruism was significant only to certain policies: those concerning diplomacy and defense, health and medical services, and welfare. The positive coefficient of altruism implies that a stronger willingness to donate increases satisfaction with certain national policies. On the other hand, because altruism was not significant to other policies, it is impossible to judge whether the willingness to donate can be used comprehensively as a proxy of social capital.

\section{CONCLUSION}

On the basis of prior social capital studies, this study investigated the relationship between social capital and national policy satisfaction. It differed from previous studies in that the focus of the dependent variable was satisfaction with national policy, as evaluated by the people. In addition, participation as an independent variable was extracted through factor analysis: participation in political networks and participation in nonpolitical networks. Although previous studies have usually employed local government and regional data, this study considered individual social capital and national policies on the assumption that performance variations among local governments were not significant, because of the weakness of decentralization in Korea. Two participation variables were tested to examine if they were associated statistically significantly with the level of national policy satisfaction.

Trust in others, which has been treated as a representative variable in previous social capital studies, was significant with regard to all policies-greater trust in others increases levels of satisfaction with national policies. Participation in political demonstrations and political debates through the Internet was not significant to satisfaction with any policy. Although many previous studies found significant positive impacts of participation in decision-making on satisfaction levels, such results can not be applied to interpret the results of this study. This is because the behaviors measured in this study do not guarantee participation in decision-making about national policy. Participation in nonpolitical networks was significant for certain policies and showed a negative coefficient. Although it is difficult to identify reasons for such results, comparison with prior studies shows a positive impact of community participation on community development and local government performance, and this study's results imply that there is another form of relationship between participation in nonpolitical networks and national policy satisfaction. Regarding the form of interaction through participa- 
tion, participation in political networks in occasional and limited: although it is a chance to express opinions, participation in political demonstration does not guarantee interactions between people and political decision process; participation in debates through the internet is done with anonymity, so interaction method is limited and indirect. On the other hand, participation in nonpolitical networks is relatively regular and direct. However additional research is needed to verify these limitations. Willingness to donate is significant to satisfaction with certain policies and not others; thus, it is difficult to assert that willingness to donate is a proper proxy of social capital.

In future studies, other significant variables should be explored in order to explain the remaining variance of policy satisfaction; models in this study have weak explanatory powers with regard to this variance. Moreover, criteria for political networks and nonpolitical networks should be more specific and diverse. In addition, future study needs to develop more accurate methods to assess citizen satisfaction with public policy and services. According to several scholars, though the survey is a common method of assessing preferences and satisfaction, one may ask a question whether such a subjective assessment is reliable (Lovrich \& Taylor 1976; Stipak 1980; Brudney \& England 1982). Regarding policy satisfaction, it is necessary to investigate the relationships between social capital and people's expectations of public policies and services. This will improve understanding of the relationship of social capital among individuals with their subjective perceptions about public policies.

Recently, there have been serious political issues that have led to political demonstrations, and individual social networks are becoming progressively more complex. There has also been a noticeable increase in interest in social donations. Consequently, studies are needed with more specific variables measuring altruism. This study assumed that previous studies in social capital did not adequately take into account situations where decentralization was underdeveloped or there was a strongly centralized state. Therefore, the approach adopted in this study may provide useful guidance to future studies concerning countries with political forms similar to Korea's.

\section{REFERENCES}

Bjornskov, C. (2003). The happy few: Cross-country evidence on social capital and life satisfaction. Kyklos, 56(1): 3-16.

Boix, C., \& D. N. Posner. (1998). Social capital: Explaining its origins and effects on government performance. British Journal of Political Science, 28(4): 686-93.

Bourdieu, P. (2001). The forms of capital. The Sociology of Economic Life, 96:111.

Brehm, J., \& W. Rahn. (1997). Individual-level evidence for the causes and conse- 
quences of social capital. American Journal of Political Science, 41(3): 999-1023. Brudney, J. L., \& R. E. England. (1982). Urban policy making and subjective service evaluations: Are they compatible? Public Administration Review, 42(2): 127-35.

Butterfoss, F. D., R. M. Goodman, \& A. Wandersman. (1996). Community coalitions for prevention and health promotion: Factors predicting satisfaction, participation, and planning. Health Education \& Behavior, 23(1): 65.

Christensen, T., \& P. Laegreid. (2005.) Trust in government. Public Performance \& Management Review, 28(4): 487-511.

Coffe, H., \& B. Geys. (2005). Institutional performance and social capital: An application to the local government level. Journal of Urban Affairs, 27(5): 485-501.

Coleman, J. S. (1988). Social capital in the creation of human capital. American Journal of Sociology, 94(S1): 95.

DeHoog, R. H., D. Lowery, \& W. E. Lyons. (1990). Citizen satisfaction with local governance: A test of individual, jurisdictional, and city-specific explanations. Journal of Politics, 52(3): 807-37.

Durlauf, S. N. (2002). On the empirics of social capital. The Economic Journal, 112(483): 459-79.

Feldman, T. R., S. Assaf, \& World Bank. (1999). Social capital: Conceptual frameworks and empirical evidence - an annotated bibliography. Washington, DC: World Bank, Social Development Family, Environmentally and Socially Sustainable Network.

Finkel, S. E. (1985). Reciprocal effects of participation and political efficacy: A panel analysis. American Journal of Political Science, 29(4): 891-913. . (1987). The effects of participation on political efficacy and political support: Evidence from a West German panel. Journal of Politics, 492: 441-64.

Fukuyama, F. (2000). Social capital and civil society. Washington, DC: International Monetary Fund, IMF Institute.

Grootaert, C., \& B. World. (1998). Social capital: the missing link? Washington, DC:World Bank.

Hanifan, L. J. (1920). The community center. Charleston, South Carolina: BiblioBazaar.

Helliwell, J. F., \& R. D. Putnam. (2004). The social context of well-being. Philosophical Transactions of the Royal Society B: Biological Sciences, 359(1449): 1435-46.

Kelly, J. M. (2003). Citizen satisfaction and administrative performance measures: Is there really a link? Urban Affairs Review, 386:855.

Knack, S. (2002). Social capital and the quality of government: Evidence from the states. American Journal of Political Science, 46(4): 772-85.

Lindstrom, M., \& E. Axen (2004). Social capital, the miniaturization of community and assessment of patient satisfaction in primary healthcare: A population- 
based study. Scandinavian Journal of Public Health, 32(4): 243-49.

Lovrich, N. P., \& G. T. Taylor. (1976). Neighborhood evaluation of local government services: A citizen survey approach. Urban Affairs Review, 12(2): 197.

Paul, S. (1987). Community participation in development projects: The World Bank experience. Washington, DC: World Bank.

Portes, A. (1998). Social capital: Its origins and applications in modern sociology. Annual Reviews in Sociology, 24(1): 1-24.

Portes, A., \& P. Landolt. (1996). The downside of social capital. The American Prospect, 26(94): 18-21.

Putnam, R. D. (1993). Making Democracy Work: Civic Traditions in Modern Italy. Princeton, New Jersey: Princeton University Press . (2000). Bowling alone: The collapse and revival of American community. New York: Simon \& Schuster.| . (2001). Social capital: Measurement and consequences. Canadian Journal of Policy Research, 2(1): 41-51.

Requena, F. (2003). Social capital, satisfaction and quality of life in the workplace. Social Indicators Research, 61(3): 331-60.

Rice, T. W. (2001). Social capital and government performance in Iowa communities. Journal of Urban Affairs, 23(3-4): 375-89.

Sabatini, F. (2008). Social capital and the quality of economic development. Kyklos, 61(3): 466-99.

Schuller, T., S. Baron, \& J. Field. (2000). Social capital: Critical perspectives. Oxford, England: Oxford University Press.

Stipak, B. (1980). Local governments' use of citizen surveys. Public Administration Review, 40(5): 521-25.

Sullivan, J. L., \& J. E. Transue. (1999). The psychological underpinnings of democracy: A selective review of research on political tolerance, interpersonal trust, and social capital. Annual Reviews in Psychology, 50(1): 625-50.

Survey of Citizen Perceptions of the Public Sector. (2006). Administration Service Monitoring. Seoul, South Korea: Gallup Korea.

Van De Walle, S., \& G. Bouckaert. (2003). Public service performance and trust in government: The problem of causality. International Journal of Public Administration, 26(8-9): 891-914.

Vemuri, A. W., \& R. Costanza. (2006). The role of human, social, built, and natural capital in explaining life satisfaction at the country level: Toward a national well-being index (NWI). Ecological Economics, 58(1): 119-33.

Welch, E. W., C. C. Hinnant, \& M. J. Moon. (2005). Linking citizen satisfaction with e-government and trust in government. Journal of Public Administration Research 
and Theory, 15(3): 371-91.

Woolcock, M. (1998). Social capital and economic development: toward a theoretical synthesis and policy framework. Theory and Society, 27(2): 151-208

. (2001). The place of social capital in understanding social and economic outcomes. Canadian Journal of Policy Research, 2(1): 11-17.

Yip, W., S. V. Subramanian, A.D. Mitchell, D. T. S. Lee, J. Wang, \& I. Kawachi. (2007). Does social capital enhance health and well-being? Evidence from rural China. Social Science \& Medicine, 64(1): 35-49.

Zimmerman, M. A. (1989). The relationship between political efficacy and citizen participation: Construct validation studies. Journal of Personality Assessment, 53(3): 554-66. 